\title{
PSIQUE Y CUPIDO, FILOLOGÍA Y MERCURIO: DIÁLOGO Y METAMORFOSIS ENTRE APULEYO Y MARCIANO
}

\author{
Julieta Cardigni \\ Instituto de Filologia Clásica, CONICET, Universidad de \\ Buenos Aires, Argentina \\ jcardigni@yahoo.es
}

\section{Resumen:}

La sátira menipea de Marciano (segunda mitad del siglo V d. C.) es una obra desestabilizadora y antididáctica. Reutiliza discursos e ideas previas de manera paródica para convertirlos en objeto de burla, atacando las convenciones y tradiciones pasadas, en un claro proyecto disolvente del saber y el discurso de la cultura clásica. En este contexto, estudiamos las 'metamorfosis' discursivas operadas por Marciano sobre las Metamorfosis de Apuleyo, su función y cómo esta contribuye al objetivo desestabilizador de la obra en su totalidad. En el diálogo entre ambos textos podemos encontrar una clave más de lectura para De nuptiis Philologiae et Mercurii.

PaLAbras Clave: Apuleyo, Marciano Capela, Transformación paródica.

\begin{abstract}
:
Martianus' menippean satire (second half of 5th Century A.D.) is an antididactic, destabilizing work. The author reutilizes previous discourses and ideas in a parodic way, in order to transform them in an object of mockery, attacking through this resource past conventions and traditions, which evidences a clear project of dissolution of classical knowledge and discourse. In this context, we aim to study the discursive metamorphosis operated by Martianus on Apuleius' Metamorphoses. Through the dialogue among both works we will undoubtedly find a valuable reading-key to approach De nuptiis Philologiae et Mercurii, an enigmatic late antique work.
\end{abstract}

KeYWORDS: Apuleius, Martianus, Parodic transformation.

\section{Influencia y Parodia: de Apuleyo a Marciano}

De nuptiis Philologiae et Mercurii es una sátira menipea que, sobre la trama narrativa de un epitalamio alegórico narrado en los dos primeros libros, despliega los saberes de las Artes Liberales, encarnados en las damas de honor de Filología que Mercurio le regala a su prometida Filología. Estas damas solemnes discurren una a una en el banquete de bodas, que se extiende a lo largo de los siete libros restantes, transformando la supuesta ceremonia de bodas en una suerte de Asamblea erudita, que le valió a la obra el mote de "didáctica" ya desde las primeras lecturas medievales. ${ }^{1}$ Este, el resumen tradicional de la obra, supone algunas cuestiones con las que no concordamos y que conviene establecer brevemente desde un principio antes de centrarnos en el objetivo del presente trabajo. ${ }^{2}$

En primer lugar, nuestra lectura del texto es global, es decir que la consideramos una obra unitaria y coherente, y no dividimos - más que de manera operativa - las dos secciones de la obra en 'mito alegórico' y 'saber científico'. En este sentido, creemos que la trama narrativa del matrimonio alegórico entre Filología y Mercurio, y el ascenso de Filología y su posterior deificación, previa a las bodas, no son simplemente el marco de la presentación de los saberes científicos, sino que constituyen la trama narrativa presente a lo largo de los nueve libros. En segundo lugar, consideramos que, en tanto sátira menipea, De nuptiis no es un manual de los saberes de la Antigüedad, sino justamente una parodia de estos saberes, de los discursos que los vehiculizan, y del discurso en general, y que postula, como contraparte, el espacio del silencio como

Recepción: 30 de abril de 2018 | Aprobación: 12 de junio de 2018 | Publicación: 05 de septiembre de 2019 
positivo. ${ }^{3}$ Finalmente, De nuptiis no utiliza la parodia como recurso retórico, sino que se construye por medio de la parodia, registro dominante a lo largo de toda la obra. ${ }^{4}$ Para determinar la presencia dominante de la parodia como registro, recurrimos al Análisis discursivo sobre la base de la Lingüística Sistémico-Funcional, que supone un acercamiento funcional al texto, ya que en este enfoque, se lo considera no sólo como producto, sino también como proceso, y así la adquisición de su sentido final se produce a partir de su relación con sus contextos (inmediato, es decir el registro; mediato, es decir los géneros discursivos). ${ }^{5}$ La parodia, detectada con precisión por este medio, se encuentra presente en todos los niveles de análisis desde los que se puede abordar De nuptiis: el lingüístico, el estilístico, el tópico, el narrativo, el genérico-discursivo.

En el presente trabajo nos centraremos en cómo Marciano Capela construye la trama de su obra por medio de la parodia del episodio de Psique y Cupido de las Metamorforsis de Apuleyo. Nuestro objetivo principal será, más que reseñar las similitudes, ${ }^{6}$ analizar el carácter de las transformaciones de Marciano y la repercusión de estas transformaciones para la interpretación de la totalidad de su obra.

Desde ya que la conexión entre Marciano y Apuleyo no es únicamente temática, sino que hay una fuerte presencia intertextual de este último en De nuptiis, y no sólo en la parte 'novelística', como tampoco únicamente proveniente de su 'novela'. Sabemos que Apuleyo filósofo fue también una fuerte influencia en la obra de Marciano y en otros autores de su tiempo. Marciano mismo parece darnos una pista en esta dirección, si estamos dispuestos a leer en tono metaliterario un pasaje del libro primero, operación que parece plausible en el contexto de una obra recorrida por muchos otros pasajes que ostentan este carácter.

Recordemos que Filología no es la primera elección de Mercurio como novia; una de sus primeras candidatas fue Psique. Han sido descartadas previamente Sofía y Mantia, la primera porque está consagrada a Palas, la segunda por su devoción a Apolo. Pero Psique recibe en el texto más atención que las dos restantes. Los regalos que le ofrecen los dioses al nacer, así como su extrema belleza, son descritos por Marciano de manera detallada. Esta descripción idílica concluye abrupta y trágicamente cuando, entre lágrimas, Virtud informa a Mercurio que la boda con Psique no será posible (I, 7):

His igitur $\Psi \nu \chi \eta \nu$ opimam superis ditemque muneribus atque multa caelestium collatione decoratam in conubium Arcas superiorum cassus optabat. Sed eam Virtus, ut adhaerebat forte Cyllenio, paene lacrimans nuntiavit in potentia pharetrati volitantisque superi de sua societate correptam captivamque adamantinis nexibus a Cupidine detineri.

(Así el Arcadio, privado de las opciones anteriores, pensó en casarse con Psique, opulenta y rica en regalos celestes y adornada por muchos atributos por parte de los celestiales. Pero Virtud, como estaba cerca del Cilenio, casi en lágrimas le anunció que [Psique] había sido raptada de su compañía por la violencia del dios de la faretra y que revolotea, y estaba siendo retenida cautiva por Cupido con cadenas de hierro. $)^{7}$

Una lectura metaliteraria de este pasaje sugiere que, en la búsqueda de una trama literaria, Marciano debe renunciar a la idea de narrar los amores de Psique, porque ya han sido relatados. Deberá, por lo tanto, realizar ciertos cambios, y el resultado será esta translatio que es, en definitiva, De nuptiis. Por otro lado, de acuerdo con la descripción de Virtud, la de Psique es una historia triste y violenta, apreciación que no se verifica en la lectura de Apuleyo. Psique nunca se encuentra prisionera, al menos no en esos términos; es Cupido el que pasa una noche en esas condiciones, encerrado en el sótano de su madre cuando Psique ha llegado allí buscándolo (VI, 11: "Interim Cupido solus interioris domus unici cubiculi custodia clausus coercebatur acriter, partim ne petulanti luxurie vulnus gravaret, partim ne cum sua cupita conveniret."; "Mientras tanto Cupido, solo, cerrado bajo llave en el sótano de la casa, continuaba detenido para que no se agravara su estado con la insolencia apasionada de su lujuria, y para impedirle el contacto con su amada."). Marciano alude quizá a que la prisión de Psique tiene que ver más bien con su cuerpo y a las restricciones que este le impone, que con una prisión real. Y dado que Marciano busca para su obra una novia que no experimente ese tipo de ataduras, la elección de Filología -que incluso ya desde sus comentaristas medievales simboliza la parte racional del alma humana, a diferencia de Psique, que se asocia con la pasional— parece más acertada. ${ }^{8}$ 
En este desplazamiento se percibe uno de los impulsos de la transformación de Marciano: elevar el relato apuleyano al ámbito de lo divino y de la contemplación del saber verdadero, alejándola del ámbito terreno de la fábula milesia. De este modo, si bien las parejas protagonistas de ambas fabulae tienen en común el provenir de diferentes mundos, Mercurio y Filología logran, en apariencia, instalarse lejos del mundo humano, mientras que Psique y Cupido, aun en un supuesto espacio divino, padecen las pasiones del cuerpo. Al respecto Relihan (The Tale..., 82) señala acertadamente que: "Cupid and Psyche (...) expresses a truth about sex and the mortal World, but its divine world is not held up for our admiration. The tale's real concerns are those of the World below."

Por su parte, la misma Filología nos confirma su alejamiento del mundo humano cuando, al recibir la noticia de su deificación, lamenta el hecho de que no podrá seguir escuchando los relatos humanos (II, 100): "Nam certe mythos, poeticae etiam diuersitatis delicias Milesias historiasque mortalium, postquam supera conscenderit, se penitus amissuram non cassa opinatione formidat." ("Pues ciertamente teme, y no es una conjetura vana, que una vez que haya ascendido al cielo, renunciará totalmente a los mitos, también a las diversidades de la poesía, a las delicias Milesias, y las historias de los mortales.”) En consonancia con esta idea, cuando Filología comienza su camino de ascenso, Cupido es expresamente dejado fuera del cortejo (II, 148): "Nam Cupido, corporeae voluptatis illex, licet eam semper antevolat, Philologiae occursibus non ausus est interesse." ("Pero Cupido, tentación del placer físico, aunque siempre vuela delante de ella, no osó figurar entre quienes salieron al encuentro de Filología."). También una alusión indirecta al protagonista del episodio apuleyano, esta aclaración parece separar a Marciano de su fuente y situar el plan de sus bodas en el ámbito del espíritu y no del cuerpo.

Vale aclarar, en caso de que alguien se lo pregunte, que ciertamente la polifonía de la voz autorial que caracteriza a De nuptiis desde el inicio (Marciano es vate o sacerdote, autor y también transmisor de la fabula creada por Satura, I,2) también lo liga a la tradición de la novela. ${ }^{9}$ Sin embargo, el tratamiento del material es diferente; tal como corresponde a la sátira menipea, Marciano no se centra en las acciones de los personajes sino en sus pensamientos, reflexiones o cambios internos, y los personajes constituyen casi ideas, en su nivel de abstracción. Si pensamos en la sátira menipea y en la novela como pertenecientes, ambas, a la anatomía, estas similitudes se explican solas y lo que cobra importancia son entonces las diferencias entre ambas formas narrativas.

\section{El TAMIZ PARÓDICO Y LAS TRANSFORMACIONES: CUERPO, SABER, DISCURSO Y SILENCIO}

Si bien las transformaciones sobre Apuleyo son perceptibles en múltiples niveles de la obra de Marciano, con fines operativos podemos señalar una serie de ejes que las articulan de manera coherente: el del matrimonio, que simboliza la unión e implica una postura sobre la relación entre cuerpo y espíritu; el del saber y la curiosidad, que funcionan como punto de llegada y de partida; y finalmente la del discurso y el silencio, categorías que a lo largo de toda la obra se van delineando como sus ejes compositivos principales.

Para empezar, recordemos que ambas historias -llamadas 'fabellae' en cada caso por sus propios narradores/autores $-{ }^{10}$ son parte de relatos mayores. Lucio, convertido en asno, escucha la historia de una anciana que la relata, intentando calmar a la novia cautiva (IV, 28). Por otro lado, Marciano narrador le propone a su hijo - a quien dedica la obra- el relato de estas bodas divinas, historia que, según él, le ha sido inspirada por Sátira, el propio género literario (I, 2: "fabellam tibi, quam Satura comminiscens hiemali pervigilio marcescentes mecum lucernas edocuit, ni prolixitas perculerit, explicabo."; "Te contaré un cuentito que Sátira me ha enseñado, y que inventó conmigo en una velada invernal mientras las luces languidecían, a menos que la extensión te desanime."). En el caso de Apuleyo, el episodio toma casi un cuarto de la obra, y en el caso de Marciano, si bien en cuanto a la proporción dentro de la obra el número sería menor (dos libros de nueve), las nupcias son a su vez la trama en la cual se inscriben de los discursos de las Artes liberales, por lo cual el relato funciona de manera transversal. 
Dicho esto, el primer tema evidente que ambas obras comparten es, sin duda, el de la unión matrimonial, si bien esta adquiere características diferentes en cada representación. En Apuleyo significa el fin de los problemas, un fin deseado, un deseo atravesado de peripecias y conflictos. En De nuptiis, paradójicamente, se anuncia desde el título, y se prepara desde el comienzo de la obra, pero nunca se lleva a cabo. Los conflictos que experimentan Mercurio y Filología son de otro orden: no el de las peripecias o aventuras, sino el de los discursos. Son las propias Artes Liberales con su incesante parloteo las que dilatan, hasta expulsarla fuera de la economía narrativa de la obra, esta planeada y aceptada boda.

Pero hay también en las Metamorfosis otra historia referida a una unión matrimonial, que es la de Lucio e Isis. Una suerte de versión sublime de la comedia de Psique y Cupido (Relihan, 2009: 82, 83: "If Psyche's tale is parallel to Lucius', one could say that Pysche's tale has an unexpectedly comic ending, while Lucius' has an unexpectedly sublime one, by contrast."), que sí aborda el tema del saber desde la iniciación a los misterios, cuestión que supera la de la mera curiosidad inicial de Lucio, y se acerca más a la figura de Filología murmurando una plegaria silenciosa con la voz de la mente para recibir la revelación. El destino de Lucio completa el contexto inmediato de Psique y Cupido y es, de alguna manera, su contratara: no por medio del cuerpo, sino por medio de la práctica de la filosofía y la iniciación, Lucio logra salvarse y volver a su estado humano, aunque convertido en un hombre nuevo y diferente.

En intrínseca relación con las bodas se encuentra el eje de lo corporal y lo espiritual, ligado a los placeres terrenales o a las especulaciones racionales respectivamente. En Apuleyo, la relación carnal es el camino para la inmortalidad y la felicidad; así Psique llega, luego de pasar por numerosas pruebas, a la unión nupcial con Cupido, que incluso tiene un fruto, Voluptas (VI, 24: "Sic rite Psyche convenit in manum Cupidinis et nascitur illis maturo partu filia, quam Voluptatem nominamus."; "Con todos esos ritos, Psique quedó en poder de Cupido, y a su tiempo nació una hija a la que llamamos Voluptuosidad."). El texto nos indica en varias ocasiones que la relación entre Psique y Cupido es sexual, tanto en sus comienzos (V, 4: "Iamque aderat ignobilis maritus et torum inscenderat et uxorem sibi Psychen fecerat et ante lucis exortum propere discesserat."; "Y es que había llegado ya el marido secreto, se había metido en la cama, había hecho a Psique su esposa y se había marchado apresuradamente."; V, 6: "centies moriar quam tuo isto dulcissimo conubio caream. Amo enim et efflictim te, quicumque es, diligo aeque ut meum spiritum, nec ipsi Cupidini comparo."; "Muera yo mil veces antes de renunciar a esta dulce unión, porque quienquiera que seas, te amo apasionadamente, tanto como a mí misma, y no te cambiaría ni por el propio Cupido."; V, 6: "Mi mellite, mi marite, tuae Psychae dulcis anima."; "Mi miel, mi marido, dulce alma de tu Psique."), como más adelante cuando Psique cae presa de la pasión al pincharse con una fecha del carcaj de Cupido:

Quae dum insatiabili animo Psyche, satis et curiosa, rimatur atque pertrectat et mariti sui miratur arma, depromit unam de pharetra sagittam et punctu pollicis extremam aciem periclitabunda trementis etiam nunc articuli nisu fortiore pupugit altius, ut per summam cutem roraverint parvulae sanguinis rosei guttae. Sic ignara Psyche sponte in Amoris incidit amorem.").

("Mientras Psique, con su insaciable curiosidad, tentaba admirada las armas de su marido, sacó una flecha del carcaj, y al palpar la afilada punta con la yema del pulgar, le temblaron las manos y se pinchó lo suficiente como para que unas gotas de sangre rodaran por la piel, y así, sin darse cuenta, cayó rendidamente enamorada de Amor.")

No es la única pasión que anima las acciones de los personajes: la envidia mueve a Venus, y la lujuria y el amor mueven, previsiblemente, también a Cupido ("Vi acpotestate Venerii susurrus invitus succubuit maritus et cuncta se facturum spopondit"; "Por mucho que le pesara sucumbió el marido a aquellas zalamerías de ardor y lujuria, y se comprometió a hacer lo que se le pedía."). También Psique es presa también de la pasión de la venganza, que ejerce con crueldad y sin remordimientos contra sus hermanas (VI, 26-27).

De nuptiis, por el contrario, expulsa de manera sistemática todo elemento que remita a los placeres del cuerpo, a los sentidos, y a cualquiera de sus realizaciones, como las pasiones. Hasta tal punto, que la anunciada boda, en la que aparentemente no surgen conflictos, no llega a concretarse, generando gran fastidio en los asistentes. Así lo vemos en las quejas de Voluptas (VII, 725): 


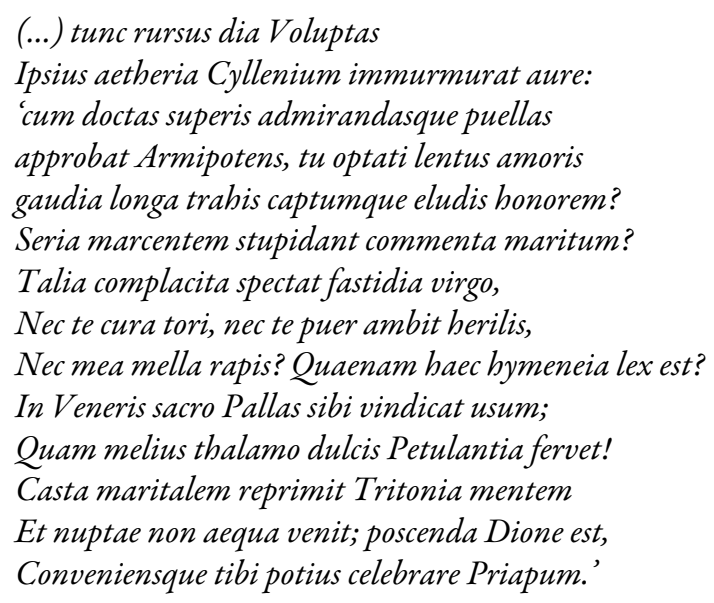

("Entonces a su vez la divina Voluptas murmura al oído celeste del mismo Cilenio [Mercurio]: 'Mientras a estas muchachas doctas y dignas de la admiración de los dioses superiores las aprueba Palas, ¿̇ú retrasas, lento, los goces del amor que deseabas y eludes el honor que obtuviste? :Acaso los discursos serios atontan a un marido decaído? La muchacha complacida observa estos fastidios, ¿pero no te preocupa el lecho, ni te ronda el niño heredero [de Venus]? ¿ni buscas arrebatar mis placeres? ¿qué ley de Himeneo es esta? Palas usurpa la práctica en una ceremonia de Venus. ¡Cuánto más apropiadamente para el lecho nupcial arde la dulce exuberancia! La casta Tritonia [Palas] reprime el ánimo nupcial y viene mal dispuesta hacia la novia. ¡Ella debería invocar a Dione! Mientras que a ti más te convendría celebrar a Príapo.’”)

Y, ya hastiada, señala Venus en su ultimátum (IX, 888):

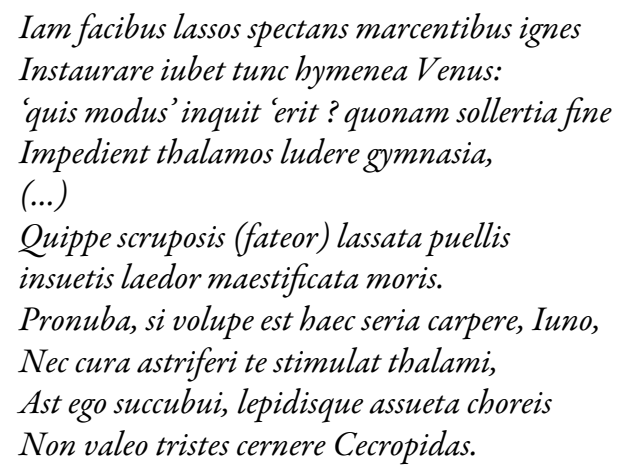

(“Al ver ya los fuegos languideciendo sobre las antorchas que se apagaban, Venus ordena recomenzar los himeneos, y dice: ¿¿de qué modo será? ¿Hasta cuándo estas prácticas doctas impedirán los juegos del lecho? (...) Confieso que realmente estoy cansada de estas muchachas pesadas, me siento triste y mortificada por estas desacostumbradas demoras. Juno Pronuba, si te place aprovechar estos discursos serios, y no te estimula la preocupación por el lecho celeste, entonces yo sucumbo; habituada como estoy a los coros alegres, no soporto observar a las tristes Cecrópidas.' ”)

El problema es, como enuncia claramente Voluptas, que los discursos de las Artes liberales demoran de tal manera la ceremonia, que finalmente la concreción sexual de la boda no se produce, con todas las implicancias alegóricas que esto tiene. La promesa dilatada de una acción, o bien su suspensión absoluta, son rasgos típicos de la menipea, que busca así frustrar las expectativas del lector y desestabilizar sus creencias arraigadas (sean estas convenciones literarias, o bien cuestiones culturales relevantes, relacionadas con la religión o la filosofía, por ejemplo). ${ }^{11}$ En este caso, Marciano se burla no sólo del saber escolar, representado por las Artes liberales, sino también del discurso, al que le niega poder y eficacia como camino de acceso al saber. El discurso es, en el universo marcianesco, más bien un obstáculo en el camino de ascenso al saber.

Por otro lado, los rasgos de cada obra activan en diferente proporción su filiación con la tradición literaria: si bien ambas habilitan una interpretación alegórica, y también ambas admiten una lectura literal, la fabula de Apuleyo se inscribe más en la tradición del cuento de hadas (“fairy tale”), mientras que la fabella de De nuptiis responde mejor a una interpretación filosófico-alegórica. Psique y Cupido proyectan su universalidad 
como personajes, y de esta manera el público puede identificarse con sus vicisitudes y destino, y confiar en que soportar las penurias tiene un sentido, ya que conduce a un final feliz. ${ }^{12}$ También es posible, ciertamente, identificar en Filología el modelo de hombre iniciado, ilustrado, quizá incluso del filósofo, y en este sentido además de su sentido alegórico puede funcionar la identificación del lector a nivel de la fabula. Asimismo, el episodio de Psique y Cupido admite una lectura filosófico-alegórica, pero lleva a ciertas incoherencias que hacen menos productiva esta interpretación. La más evidente es que la curiosidad y las pasiones, que resultan en una suerte de 'saber del cuerpo', conducen a la felicidad y a la inmortalidad, cosa que desde cualquier versión de la tradición platónica ante la que nos encontremos es inaceptable. ${ }^{13}$ Por otro lado, las complejas alusiones alegóricas de De nuptiis no solo pueden convivir entre sí en casi total armonía, sino que enriquecen la interpretación de la obra y completan su sentido profundo. ${ }^{14}$ En conjunto responden, sin mayor incoherencia, al ciclo de ascenso neoplatónico, que, si bien parodiado, se presenta de manera reconocible.

Por otro lado, ambas obras parecen compartir conceptos similares en cuanto a lo que significan discurso y silencio dentro de su universo narrativo. Es cierto que el tema del discurso y su relación con la verdad es tan antiguo como -al menos- Platón, pero en el marco de la tradición platónica tardía recobra un interés fundamental, sobre todo en relación con el objetivo de la lectura e interpretación de los textos platónicos. ${ }^{15}$ Así, en la búsqueda de nuevas formas para ordenar la heterogeneidad de una época de crisis, el tema del silencio parece eclosionar en la Antigüedad Tardía, en que surge un hastío del discurso sobre todo a partir del carácter ficcional que se le asigna casi sin excepción. Será el cristianismo el encargado de, entre otras muchas cosas, refundar la verdad del discurso sobre la base de la revelación. ${ }^{16}$ En el marco del neoplatonismo que impregna la obra de Marciano Capela, el discurso es parodiado y atacado en todas sus dimensiones y niveles, a causa de su propia naturaleza, como objeto principal del registro paródico que recorre la obra. Un poco remedando la idea de pensamiento no discursivo afín a Plotino y el neoplatonismo, Marciano deja fuera de su burla lo único que no puede ser parodiado: el silencio.

El discurso es atacado como forma de comunicación humana, por ejemplo, por medio de la ridiculización y crítica a las densas exposiciones de las Artes Liberales. Ya cuando ha hablado Gramática, la primera de las damas, el auditorio empieza a dar muestras de aburrimiento, y Palas corta su discurso (III, 325-326): "Haec cum Grammatice velut rerum exordium instauratura dixisset, propter superi enatus Iovisque fastidium Minerva talibus intervenit: '(...)si ab scholaribus inchoamentis in senatum caelitem duces, decursae peritiae gratiam deflorabis.”" "Cuando Gramática hubo dicho esto, como para preparar la introducción de estas cosas, a causa del fastidio del Senado celeste y de Júpiter, Minerva intervino diciendo así: '(...) si tú traes estas enseñanzas desde los comienzos escolares al Senado de los celestes, echarás a perder el reconocimiento de la pericia que has demostrado.'”)

También Dialéctica pone a prueba la atención de los asistentes (IV, 423-424):

Talibus insistente Dialectica et ad quaedam non minus inextricabilia quam caligosa
properante, Pallas nutu Maiugenae festinantis intervenit:
Perita fandi, iam progressum comprime,
Ne inflexa tortos stringat intimatio
Et multinodos perpeti anfractus diu
Hymen recuset.

(“Mientras Dialéctica insistía en estas cosas y se apresuraba a exponer ciertas cosas no menos abstrusas y oscuras, Palas intervino ante un gesto del hijo de Maia [Mercurio] que estaba ansioso: 'Experta en hablar como eres, reprime ya el avance de tu exposición, para que la profundización no se enrosque en vueltas tortuosas, e Himeneo no rechace los nudos de eternas vueltas.")

Pero también se critica al discurso como forma de creación literaria, ${ }^{17}$ por medio de las discusiones entre Marciano y Sátira que no llevan a ningún lado, y menos ciertamente a un aprendizaje del pretendido 
discípulo. Los intercambios van aumentando en el grado de rispidez hasta que Sátira pierde la paciencia, cuando Marciano introduce un incidente cómico antes de la entrada de la última dama, Astronomía (VIII, 806):

'Felix vel Capella vel quisquis sis, non minus sensus quam nominis pecudalis, huius incongrui risus adiectione desipere vel dementire coepisti. Ain tandem? Non dispensas in Ioviali cachinnos te movisse concilio verendumque esse sub divum Palladiaque censura assimulare quemquam velut cerritulum garrientem? At quo etiam tempore Cupido vel Satyrus petulantis ausus procacitate dissiliunt? Nempe cum virgo siderea pulchriorque dotalium in istam venerabilem curiam ac deorum ventura conspectus. apage sis nec postidhac nugales ausus lege hymeneia et culpae velamine licentis obnuberis. saltem Prieneiae ausculta nihilum gravate sententiae et, $\nu$ o ovos $\lambda v p a s$.

('Félix, o Capela, o quienquiera que seas, con un sentido que combina con el nombre que llevas, ¿te volviste loco con la intrusión de semejante escena cómica? Tienes que darte cuenta de que trajiste la risa a una Asamblea celestial y que es un acto reprobable a los ojos de los dioses, y de Palas en particular, presentar a alguien hablando tonterías como un loco, ¿y en esa ocasión osas presentar a Cupido y a Sátiro actuando como insolentes, al mismo tiempo que la doncella de las estrellas [Astronomía], una de las más hermosas de las damas ofrecidas en dote, está por presentarse al senado, y ante la vista de los dioses? Basta de eso, y después no intentes defender esta tontería o de justificar tu conducta como una licencia apropiada a una ceremonia nupcial. Por lo menos haz honor a la frase del sabio de Priene: a menos que seas un asno que escucha la lira, [reconoce el momento oportuno].' ") ${ }^{18}$

Pero tampoco en el cielo 'Olímpico' (un espacio divino de cartón pintado) la palabra funciona entre quienes la detentan con sabiduría, como los filósofos inmortalizados por sus saberes, que discuten como perros en el cielo, aullando y ladrando sin comprenderse ni ser comprendidos, no poder elevar su tono por encima de la música de las esferas (II, 56): ${ }^{19}$ "qui quidem, omnes inter Musarum carmina concinentum audiri, licetperstreperent, nullo potuere rabulato." "Todos ellos, sin embargo, aunque gritaban fortísimo, no lograban hacerse oír de ninguna manera con su ladrido rabioso por sobre el canto de las musas que armonizaban entre sí.")

En contraposición, el silencio cobra protagonismo en el pasaje final del ascenso de Filología, cuando por medio de su plegaria silenciosa recibe la revelación de la verdad. En este episodio Filología solo 've', pero no escucha ni dice nada (II, 200-208): ${ }^{20}$

Ipsa quippe Philologia lectica desiliens, cum immensos luminis campos aetheriaeque tranquilitatis verna conspiceret ac nunc tot diversitates cerneret formasque decanorum, (...) iuxta ipsum extimi ambitus murum annixa genibus ac tota mentis acie coartata, diu silentio deprecatur, veterumque ritu vocabula quaedam voce mentis inclamans secundum dissona nationes, numeris varia, sono ignota, iugatis alteratisque litteris inspirata, veneraturque verbis intellectualis mundi praesules deos eorumque ministros sensibilis sphaerae potestatibus venerandos, universumque totum infinibilis patris profundidtate coercitum, poscitque quosdam tres deos aliosque diei noctisque septem radiatos. quandam etiam fontanam virginem deprecatur, secundum Platonis quoque mysteria $\alpha \pi \alpha \xi \kappa \alpha \iota ~ \delta i \zeta \varepsilon \pi \varepsilon \kappa \varepsilon \varepsilon v \alpha$ potestates. Hic diutissime florem ignis atque illam existentem ex non existentibus veritatem toto pectore deprecata, tum visa se cernere apotheosin sacraque meruisse. Quippe quidam candores lactei fluminis tractim stellis efflamantibus defluebant.

("Ciertamente la propia Filología desciende de la litera de un salto, contempla los extensos campos de luz y la primavera de etérea paz, y ya observa las variedades y formas de los decanos, (...) Filología, arrodillándose justo al lado del muro del cielo más extremo, y concentrando toda la agudeza de su mente, profiere una larga plegaria en silencio, y exclamando con la voz de la mente, conforme al ritual de los antiguos, ciertos vocablos, diferentes según los distintos pueblos, de cifras diversas, de sonidos desconocidos, pronunciados combinando y alterando letras, no solo venera, con sus palabras, a los dioses que presiden el mundo inteligible y a sus ministros, a los cuales las potestades de la esfera sensible deben respeto, y al universo entero, contenido por el abismo del padre infinito, sino que implora a ciertos tres dioses y a otros que brillan los siete días y noches. Suplica también a cierta fuente virgen, y también, siguiendo los misterios de Platón, a las potestades 'una y dos veces más allá. Entonces, tras haber rogado larguísimo tiempo, con todo su corazón, a la flor del fuego y a aquella verdad existente a partir de lo no existente, entonces le pareció ver que había ganado la apoteosis y la consagración: como si una blancura de un río como de leche fluía lentamente entre las llameantes estrellas."

Con estas ideas en mente, es posible encontrar un reflejo de la dualidad silencio-discurso en Apuleyo, en particular en dos elementos. En primer lugar, Psique, atada al terreno de lo humano, y que a través de las pasiones humanas logrará la salvación y la felicidad, inicia su primera etapa de 'casada', luego de ser raptada 
por Cupido, oyendo voces y sin poder ver nada de lo que la rodea. Ni a sus sirvientes, ni a su propio marido. Pero sí los escucha constantemente hablar, e incluso cantar $(\mathrm{V}, 2)$ :

\footnotetext{
Haec ei summa cum voluptate visenti offert sese vox quaedam corporis sui nuda et: "Quid," inquit "domina, tantis obstupescis opibus? (...). Nos, quarum voces accipis, tuae famulae sedulo tibi praeministrabimus (...)."

("Mientras estaba observando con arrobo todas esas cosas, la abordó una voz sin cuerpo que le decía: 'Por qué te quedas aturdida ante tantas riquezas? (...) Los de las voces que estás oyendo somos tus criados, y vamos a estar cerca de ti para servirte con esmero, (.....")
}

Como una reafirmación de que su ámbito es el terreno, aun cuando topológicamente esté en ámbito divino, Psique convive con el discurso y sólo con el discurso. El ámbito divino-Olímpico con el que tiene que lidiar es uno lleno de discursos e historias, relatadas o recordadas por los propios dioses que se encuentra en su camino. Por el contrario, señala Relihan (The Tale...: 83), la unión final de Lucio con Isis a través de la iniciación en sus misterios, que culmina en una vida célibe y devota, se caracteriza, entre otras cosas, por la falta de discurso y de historias acerca de las divinidades. ${ }^{21}$ En contraposición con los dioses olímpicos, que son protagonistas de la fabula cómica -y que se parecen mucho a los dioses del Olimpo marcianesco- Isis no es representada a través de ninguna ficción, dado que, en tanto verdad, se encuentra por encima de todo discurso.

Finalmente, el tema que congrega todos los que hemos revisado es el del saber, como búsqueda central en De nuptiis, y se refleja en la curiosidad que mueve las acciones de muchos personajes de las Metamorfosis. Es por curiosidad y deseo de aprender las artes de la magia que Lucio es transformado en asno (III, 19; 3. 24) es también por curiosidad que Psique provoca su propia caída (V, 23) y aun en medio de sus desgracias, no ha aprendido aún y persiste en el error al abrir la caja que le encarga Venus con el secreto de la belleza, (VI, 20,21), de manera análoga a Lucio (o más bien Fotis), que en su afán se equivoca de caja. Sin embargo, este sentimiento es productivo en Apuleyo, ya que conduce a finales felices, y a la resolución de los conflictos que genera. De alguna manera la curiositas es el motor que hace avanzar el relato. ${ }^{22}$ También en Marciano la curiosidad es positiva desde el primer momento, ya que es lo que ha llevado a Filología a su familiaridad con el saber, que ahora le permite ser elegida como prometida de Mercurio.

Asimismo, en De nuptiis el saber está tematizado de muchas formas, y adquiere un carácter central como eje temático. A diferencia de lo que ocurría en Apuleyo, en Marciano la curiositas va acompañada de afán y trabajo, lo que transforma este sentimiento inicial en motor de un camino de ascenso más complejo y completo, por el cual Filología debe transitar. En De nuptiis, el saber es objeto de búsqueda, identificable con la verdad trascendente, por un lado. Por otro, es un conjunto de disciplinas -las Artes Liberales - que aburren, se repiten y no nos llevan a ningún lado. En tanto verdad, el saber es el objetivo central de la unión, alegorizada en el motivo de las nupcias, ya que Mercurio y Filología representan la elocuencia y el saber, respectivamente; lo divino y la parte racional del alma; los saberes del trivium y del quadrivium, y quizá todas las anteriores juntas. Por el contrario, en tanto discurso humano, el saber es el obstáculo para la unión.

\section{Las Metamorfosis transformadas y las Bodas SILENCIOSAS}

¿Cuál es entonces el sentido de las transformaciones que Marciano realiza sobre la obra de Apuleyo? Para algunos parecen referirse, sobre todo, a la proyección espiritual de la presentación terrena que se hace en Metamorfosis, ofreciendo la alternativa del matrimonio 'espiritual', rechazando y desplazando constante y explícitamente cualquier elemento que tenga que ver con el cuerpo, con la pasión, con los placeres. O bien se trata de una obra que subvierte los moldes novelísticos, y se configura en este movimiento como una sátira menipea. Estas posturas, que no dejan de ser acertadas, no explican lo suficiente -a nuestro entender - cuál es el efecto profundo de las transformaciones de Marciano en la construcción del universo de De nuptiis.

Si ampliamos el panorama y observamos el episodio de Psique y Cupido dentro de la trama general de Metamorfosis, es posible apreciar que funciona en paralelo con la historia del propio Lucio, que termina sus 
aventuras salvado por Isis, consagrado a ella, casado con ella, pero llevando una vida célibe. Como ya hemos mencionado, a nivel del relato general, Lucio encuentra, en tanto iniciado, cierta unión con la verdad, de la cual las bodas de Psique y Cupido son la contraparte cómica.

Por lo tanto, ¿por qué no pensar que Marciano está parodiando no sólo el episodio de Psique y Cupido, sino toda la obra de Apuleyo? Desde esta perspectiva la transformación de De nuptiis cobra otro sentido, más en consonancia con la interpretación en clave paródica que proponemos de la obra. Marciano no sólo es la contracara sublime y espiritual de la unión carnal y festiva de Psique y Cupido, sino que, en otro tipo de transformación, es también la contracara de la unión espiritual y célibe que experimenta Lucio con los misterios de Isis. Filología, como Lucio, es también una 'iniciada', dado que ha experimentado, al mejor estilo plotiniano, la unión -breve y transitoria - con lo Uno, lograda a partir de la plegaria silenciosa (II, 200-208). En contraste con el bullicioso cielo Olímpico al que después ingresa para su ceremonia de bodas, Filología experimenta en silencio la revelación y la unión con la verdad, que le concede la inmortalidad luego de su largo camino de ascenso. Pero el hecho es que ese acceso al conocimiento verdadero queda desdibujado y perdido en el marco del resto de la obra, que se desarrolla en el cielo Olímpico, en el cual Filología debe escuchar nuevamente todas las Artes que vomitó antes de iniciar su camino, en una suerte de ciclo in-trascendente en el cual queda claro que el discurso nos ata a nuestro ser terreno, y nos retiene en el ámbito del conocimiento escolar y humano.

En relación con esto, la metamorfosis que experimenta Lucio no se verifica en el destino de Filología. Lucio vuelve a su condición humana como un hombre diferente, mientras que Filología, luego de su camino de ascenso, solo encuentra que ha vuelto a iniciar el ciclo de las Artes liberales en un espacio divino más bien dudoso, llenado por discursos interminables y tediosos, sin perspectivas de concretar el matrimonio y sin siquiera cambiar palabras con su prometido.

La verdadera parodia de Marciano, entonces, no es a la comedia sino al relato sublime. Las bodas de Filología y Mercurio son, por oposición, parodia de los amores de Psique y Cupido, en los que la pasión es el camino de ascenso. En Marciano este camino está negado explícitamente, para abrir como alternativa el del ascenso espiritual. Sin embargo, este camino espiritual, que remeda la iniciación de Lucio, tampoco conduce a ningún lugar trascendente definitivo. En este sentido, las bodas de Filología y Mercurio son, por analogía, parodia de la unión sublime entre Lucio e Isis. Como buena sátira menipea, De nuptiis no nos deja alternativa: somos humanos por las pasiones, o somos humanos por el discurso, pero en cualquier caso estamos atados al estado terrenal.

El análisis de la parodia deja en evidencia una lógica habitual de la obra literaria tardoantigua, que parece cerrarse sobre textos previos para su composición, transformándolos y resignificándolos. El resultado es un universo literario que, lejos de reflejar la realidad, se construye de manera misteriosa y simbólica, pero no menos eficaz en sus posibilidades de representación de la verdad. Excepto, por supuesto, que decidamos creer, con Marciano, que no es el discurso lo que nos llevará allí, sino el silencio.

\section{Notas}

1 En esta dirección - con las debidas variantes en cada caso- leen De nuptiis, entre otros, Westra, H. (1981, “The Juxtaposition of the Ridiculous and the Sublime in Martianus Capella”, Florilegium, vol. 3 (1981): 198-214; 1998. “Martianus prae/postmodernus?”, Dionysius 16:115-122.”. Book I, Leiden, Mittellateinische Studien und Texte 20); Petrovicova, E. (2010. "Martianus Capella als subversiver Parodist der Fähigkeiten menschlicher Erkenntnis? Frage der Zugehörigkeit von De nuptiis Philologiae et Mercurii zur Gattung der Menippeischen Satire”, Acta antiqua Academiae); Bakhouche, B. (2011, "Martianus Capella's De nuptiis Philologiae et Mercurii or the Subversion of the Latin Novel”, Marília P. Futre Pinheiro, Stephen J. Harrison, Fictional Traces. Reception of the Ancient Novel, vol. 2, Barkhuis).

2 Nuestra lectura se acerca más a las visiones de Relihan, J. (1993, Ancient Menippean Satire, Baltimore, Johns Hopkins University Press); Shanzer, D. (1986, A Philosophical and Literary Commentary on Martianus Capella's De Nuptiis Philologiae et Mercurii book I, Berkeley, University of California Press); y parcialmente a la de Bakhouche (2015, "Jeu 
de miroirs dans les intermèdes auctoriaux des Noces de Philologie et Mercure de Martianus Capella”, Latomus, vol. 74 (2015): 417-440).

3 En concreto, el más relevante es el de la plegaria silenciosa de Filología, que culmina su viaje de ascenso en II, 200-208.

4 La exposición de estos resultados de investigación, que no podemos exponer aquí en detalle, se encuentra en el libro en preparación De nuptiis Philologiae et Mercurii o la farsa del discurso: una lectura literaria de Marciano Capela (en preparación 2018 para su publicación por la Editorial de la Facultad de Filosofía y Letras de la Universidad de Buenos Aires).

5 Sobre el análisis discursivo desde la Lingüística Sistémico-Funcional, vid. Hallliday, M. A. K. 1989. Language, context and text: aspects of language in a social-semiotic perspective, Oxford, Oxford University Press; Halliday, M.A.K \& Hasan, R. 1976. Cohesion in English, Londres, Longman; Halliday, M. A. K. \& Mathiesen, Ch. 2004. An introduction to Functional Grammar, Londres, Arnold; Eggins, S. \& Martin, J. R. 2003. "El contexto como género: una perspectiva lingüístico- funcional”, Revista Signos, 2003, vol. 36, n. 54: 185-205; Martin, J. R. 1992. English Text. System and Structure, Amsterdam, John Benjamins, y 1997. “Analyzing Genre: Functional Parameters”, Christie, F. \& Martin, J. R. (eds.) Genre and Institutions, Londres, Routledge; Martin, J. R. \& Rose, D. 2007. Genre relations: mapping culture, Londres, Equinox; Menéndez, S. M. 2006. ¿Qué es una gramática textual?, Buenos Aires, Litterae Ediciones.

6 Han ya notado el episodio de Psique y Cupido como base de la fabula de De nuptiis Bakhouche (“Martíanus Capella’s De nuptiis...”); Ramell, I. (ed., 2001 Marziano Capella. Le nozze di Mercurio e Filologia, Milano, Bompiani), entre otros. En la edición de Marciano Capela de Teubner, a cargo de Willis, J. (ed. 1983, Martianus Capella, Lepizig, Teubner), pueden verse las numerosas alusiones intertextuales que los dos primeros libros de De nuptiis presentan con respecto a las Metamorfosis de Apuleyo. También Joel Relihan, en su traducción del episodio de Psique y Cupido (2009, The tale of Cupid and Psyche. Apuleius, Hackett Publishing), aborda la cuestión de cómo esta trama narrativa se proyecta a la obra de Marciano.

7 Sigo el texto latino de Ramelli (2001), basado en el de Willis (1983), y las traducciones son mías.

8 Sobre los comentaristas medievales de De nuptiis, vid. Ilaria Ramelli (ed. 2006, Tutti i commenti a Marziano Capella, Milano, Bompiani). Ya desde su recepción medieval De nuptiis fue leída de manera obsesivamente alegórica, proponiéndose diversas variantes para el significado de los novios y de su unión, variantes que a menudo pueden convivir en la interpretación de la obra.

9 Sobre Marciano Capela y los moldes novelísticos en De nuptiis, vid. Bakhouche (“Martianus Capella’s De nuptiis...”). La autora realiza una serie de interesantes observaciones que dan cuenta de las diferencias entre Marciano y Apuleyo; sin embargo, no las enmarca en el hecho de que Marciano, precisamente, escribe una sátira menipea y no una novela, lo cual justifica la mayoría de las transformaciones señaladas. Entre los elementos de molde novelístico de que Marciano se sirve podemos hablar de unidad de tiempo y espacio (la acción transcurre en una noche, y el escenario principal es el cielo Olímpico, excepto en el libro 2 que se narra el ascenso de Filología), y se trata de una historia de amor (si bien despojada de elementos románticos, dado que Mercurio elige a Filología por conveniencia, y nunca se hablan durante toda la obra), que no encuentra oposición ni conflicto real (salvo quizá los inacabables discursos de las damas de honor que, de hecho, dilatan la unión marital). Sobre la sátira menipea antigua vid. Relihan (Ancient Menippean...).

10 Apuleyo denomina así a su historia desde el principio (I, 1: "At ego tibi sermone isto Milesio uarias fabulas conseram auresque tuas beniuolas lepido susurro permulceam (...)”. Así la llama también Lucio una vez que la anciana ha finalizado el relato (texto), y también Marciano en dos ocasiones, cuando la introduce a su hijo (I, 1: “fabellam (...) tibi explicabo") y en el Epílogo (IX, 997: "Habes anilem fabulam”, también de reminiscencias apuleyanas), cuando concluye y se disculpa con él por el fracaso de su empresa.

11 Sobre los rasgos de la menipea, antigua y moderna, vid. Relihan, Ancient Menippean Satire.

$12 \mathrm{Al}$ respecto señala Relihan (The Tale..., 82) que este relato como espejo de la suerte que corren otros personajes (Cárite, el propio Lucio) es una desilusión, ya que ninguno de ellos encontrará la felicidad o la salvación por medio del amor carnal, y en este sentido es una promesa no cumplida.

13 Recordemos que la filiación neoplatónica de Apuleyo, visible sobre todo en sus obras filosóficas, es innegable.

14 Sobre la interpretación de la alegoría en De nuptiis, su construcción y función, vid. Gersh, S. (1986, Middle Platonism And Neo-Platonism: The Latin Tradition, (2 vols.), "Publications in Medieval Studies", vol. 39, Indiana, University of Notre Dame Press); Shanzer, D. (A Philosophical and Literary Commentary...).

15 Para una excelente y completa revisión de las concepciones metaliterarias en el neoplatonismo, vid. A. Coulter (1970, The Literary Microcosm: Theories of Interpretation of the Later Neoplatonists (Columbia Studies in the Classical Tradition, Columbia University Press). Sobre la idea de una 'póética del silencio' en el Tardoantiguo, vid. Hernández Lobato (2017, “To Speak or not to Speak”, en J. Elsner-J. Hernández Lobato, The poetics of Late Latin Literature, Oxford University Press) y Cardigni, J. (en preparación 2018, De nuptiis Philologiae et Mercurii: una lectura literaria de Marciano Capela, Editorial de la Facultad de Filosofía y Letras, Universidad de Buenos Aires), especialmente sobre el discurso y el silencio en Marciano Capela. 
16 Sobre el tema de la ficción en la Antigüedad Tardía, vid. A. Cullhed (2015, The Shadow of Creusa: Negotiating Fictionality in Late Antique Latin Literature, De Gruyter, Berlin).

17 La desconfianza en el discurso ya desde Platón podía sortearse de alguna manera por medio de la forma "diálogo". Vale la pena señalar entonces que Marciano ataca también la forma dialógica como escape a los problemas del discurso, ya que lo primero que se ridiculiza son los intercambios entre Sátira y Marciano, conarradores de la obra.

18 Completo el refrán, como lo hacen varias traducciones de Marciano, para que el sentido del pasaje tenga mayor claridad.

19 Sobre este último tema, vid. Cardigni, J. (2017, "Perros y filósofos en De nuptiis Mercurii et Philologiae de Marciano Capela”, Revista de Estudios Clásicos, Universidad Nacional de Cuyo (2016), ISSN 0325-3465; eISSN 2469-0643.

20 Fernando Navarro Antolín (2016, Las nupcias de Filología y Mercurio, vol. 1 Las bodas misticas, Madrid, Alma Mater:151, n.554) ha ya notado las similitudes de este pasaje con Macrobio (Comm in Somn. Sc. I,15). Filología, desde la octava esfera -el cielo de las estrellas fijas-, observa la estructura astronómica del universo: los decanos, los 84 liturgos, los cuerpos celestes y sus órbitas, los polos y el eje del cielo.

21 "And, perhaps most important, the Isis who saves Lucius is a goddess without a story. Cupid and Psyche is a tale of comic Olympian gods, and of goods behaving badly. Why would anyone look to this Venus, this Cupid, this Jupiter, for truth or consolation? It is the very fact that they are characters in a story that convicts them of triviality and irrelevance. When Lucius is claimed by Isis, we hear nothing of the stories we know elsewhere about Isis, Osiris, Horus and Seth; (...) Truth is outside of story and fiction."

22 Desde ya, existe una tensión en Apuleyo con respecto a este tema de la curiositas. Si bien el final feliz de la historia entre Psique y Cupido parece transmitir un mensaje positivo, no será muy feliz el final de quien escucha el relato, y hacia quien parece ir dirigida, en primera instancia, esta enseñanza. 